\title{
ILUSIONES COMPARTIDAS ENTRE LA ALBÚMINA* Y EL ÓLEO. LAS TARJETAS DE VISITA DE CRUCES Y CAMPA
}

\author{
Patricia Massé \\ El retrato (como la fotografía) \\ es una parte del ser. \\ Julián Gállego
}

En la segunda mitad del siglo pasado el retrato fotográfico tarjeta de visita imperó como una moda en la sociedad mexicana; lo mismo sucedió en Europa y el resto de América. De hecho algunos álbumes familiares todavía cuentan con esos retratos y, no se diga, los principales centros de acopio de documentos históricos.

El tamaño de los retratos tarjeta de visita, que es de nueve por seis centímetros aproximadamente, favoreció el gusto por el intercambio y la colección de los retratos fotográficos de familiares, amigos y personajes famosos de la época.

En la mayoría de esos retratos que conocemos se observa un patrón que se repite constantemente: el cuerpo erguido en posición frontal o de tres cuartos de perfil; el rostro expuesto hacia la cámara lo más ampliamente posible (por lo general se aprecian las tres cuartas partes del mismo); la actitud es reposada; la balaustrada, la columna, la mesa o la silla son el soporte recurrente donde se apoya el antebrazo o la mano del modelo; la disposición de las manos (que es en todos los casos un punto importante en los retratos a los que nos referimos) refuerza la serenidad y la contención del gesto del retratado.

A lo anterior se suma la receta formulada por el francés André-Adolphe Disdéri, quien registró la patente de los retratos fotográficos del tamaño de una tarjeta de visita en 1854. Para garantizar un retrato de "buena calidad" recomendó dicho fotógrafo lo siguiente: un gesto agradable; la posición y las proporciones naturales; nitidez general en la imagen; las

\footnotetext{
* Las impresiones fotográficas en albúmina emplearon, como medio de suspensión, la clara de huevo para retener las sustancias sensibles a la luz -el nitrato de plata-; ésta formaba una capa compacta en la superficie del papel, soporte de la imagen. Su uso se generalizó entre 1855 y 1895 , y su cualidad consistió en permitir una alta definición en los detalles, un buen contraste de tonalidades y una gran brillantez
} 
sombras, las medias tintas y los claros bien pronunciados, estos últimos brillantes; fondos naturales y detalles en los oscuros. ${ }^{1}$

De la combinación de los elementos citados tiende a resultar, por lo general, una representación sometida a un molde rígido, donde observamos una figura detenida en una postura que desvanece su personalidad.

Entre los retratos fotográficos tarjeta de visita que se produjeron en nuestro país en el siglo pasado, los de Cruces y Campa muestran, en varios casos, un alejamiento del modelo anotado; en ellos salta a la vista su originalidad. La sorpresa de esta primera impresión ha sido doble al hallar ciertos vínculos entre algunos de esos notables ejemplares y determinados retratos pintados a mediados del siglo pasado.

La causa del asombro tiene que ver con dos circunstancias. Primero, con el reproche que algunos interesados en la materia hacen al retrato tarjeta de visita: censuran su escaso valor estético, así como su descuido en la búsqueda del carácter del modelo ${ }^{2} \mathrm{y}$, manifiestan que lo documental, lo mecánico y lo trivial son los atributos que resaltan en una primera impresión. ${ }^{3}$ Segundo, porque a pesar de la proximidad entre las pinturas y las fotografías observadas, cada cual ofrece una imagen singular.

A continuación serán comentadas las cualidades que se revelan en cada caso, ${ }^{4}$ previa identificación de las especificidades de las artes que se confrontan, así como de los fotógrafos Cruces y Campa.

\section{Especifidades de la fotografía}

El retrato fue, desde los inicios de la fotografía, uno de los usos más importantes para los que fue destinada la nueva técnica patentada por Daguerre. En un principio, cuando se requería que el modelo se mantuviera inmóvil por un tiempo de dos minutos, aproximadamente, se recurrió a un patrón de pose que sometía a condiciones poco favorables a quien se

\footnotetext{
${ }^{1}$ André A. E. Disdéri, L'art de la photographie, París, (s.e), 1862, apud, Gisèle Freund, La fotografía como documento social, 3a ed., Barcelona, Editorial Gustavo Gili, 1983, p. 64

${ }^{2}$ Cfr. Beaumont Newhall, The History of Photography, 5a ed., New York, The Museum of Modern Art, 1982

${ }^{3}$ Cfr. Arnold Gassan. A Chronology of Photography. A Critical Survey of the History of Photography as a Medium of Art, Ohio, Handbook Company, Athens, 1972 p. 15

${ }^{4}$ Los retratos fotográficos originales que serán comentados forman parte del acervo que posee la Fototeca del Instituto Nacional de Antropología e Historia. De las pinturas sólo se contó con la observación de los originales que se encuentran en el Museo Nacional de Arte y en el Museo de San Carlos; de manera que en algunos casos las reproducciones en los libros fueron mi único punto de contacto con la obra
} 
retrataba; por ello las personas mostraban, por lo general, un gesto duro. Las limitaciones técnicas del proceso recientemente descubierto rebasaban las expectativas del entonces daguerrotipista. Dos motivos, principalmente, restringieron la actividad de éste: la baja sensibilidad de la placa fotográfica donde se capturaba la imagen, gracias a la acción de la luz (un soporte de cobre sensibilizado con un compuesto de yoduro de plata) y las imperfecciones de la lente de la cámara.

Para la época en que van a ser situadas nuestras observaciones, esto es, para la segunda mitad del siglo xIX, los adelantos en la práctica fotográfica habían aligerado las tortuosas condiciones para la toma del retrato. La mayor luminosidad de la lente o, en todo caso, de las cuatro lentes utilizadas para la toma de retratos tarjeta de visita (que permitían operar cuatro u ocho exposiciones separadas pero capturadas en una sola placa), así como el empleo del colodión húmedo (que proporcionó mayor sensibilidad a la placa negativa), introdujeron cambios en la práctica fotográfica al abreviar el tiempo de toma del retrato a algunos segundos. Por lo que a resultados se refiere, podemos observar que, no obstante que en los años sesenta y setenta aún era habitual el empleo del sujetador del torso que el fotógrafo ajustaba a la persona que retrataba (y que seguía restringiendo la libertad del modelo), la rigidez y dureza en el gesto del retratado ya podían ser evitados, sin poner en riesgo el consabido retrato.

En un principio la verosimilitud se identificó con la imagen fotográfica; ésta era portadora de una ilusión: la del tiempo capturado y, en el caso del retrato, la ilusión de que la persona estaba realmente allí. La particular carga de significado que envolvió al retrato hecho con la cámara fotográfica tiene que ver con la imagen en sí misma; en ella se recoge una fracción de "tiempo real", vivido por la persona retratada; es un instante de vida capturado: el tiempo detenido por la mediación de un aparato que, supuestamente, reproduce con exactitud la realidad.

En relación con el momento histórico se ha dicho que la fotografía surgió en una época en que prevalecía el deseo de ver la realidad como ésta aparecía ante un espejo. Por otra parte, la idea de "identidad individual" había ganado una notoria importancia social; el deseo de afirmación del "individuo", que no tenía mucho de haber sido reconocido como entidad política (apoyado en el principio de democracia), encontró en el retrato fotográfico al transmisor ideal. ${ }^{5}$ Todo el empeño estaba puesto en la autoafirmación, en el afán de ser aceptado por los demás. La fotografía,

\footnotetext{
${ }^{5}$ Cfr. Alain, Corbin. "El secreto del individuo", en Philippe Ariès y George Duby, Historia de la vida privada, tomo 4, Madrid, Taurus Ediciones, 1989.
} 
cuyo principio de fidelidad a la realidad era, a la sazón, incuestionable, será el medio a través del cual se exaltará todo aquello que, a la vista de los demás, dignifique a la persona: el vestido, el peinado y los accesorios; todo ello arreglado de acuerdo con un repertorio de ademanes.

En función de esas aspiraciones el fotógrafo se asume (salvo escasas excepciones) no como artista, sino como un artesano cuyo principal propósito es el de hacer bien su trabajo; para ello requiere, ante todo, del dominio de una serie de habilidades técnicas para plasmar el retrato de una persona.

Captar al modelo con un gesto natural, constituía una de las dificultades que el fotógrafo enfrentaba con mayor frecuencia en la toma de un retrato. Entre las tarjetas de visita escasean los retratos ejemplares; el patrón que se generalizó y el código cifrado por Disdéri para la toma de esos retratos (el cual ha sido mencionado al principio del texto) fue, en casi todos los casos, la fórmula que resolvió de manera fácil e inmediata el trabajo del fotógrafo retratista.

\section{Especificidades de la pintura}

La pintura de retrato en nuestro país experimentó un auge durante el siglo XIX. En la Colonia los temas de mayor demanda para los pintores habían sido de carácter religioso (no obstante que los retratos individuales de importantes dignatarios, damas de la alta sociedad y religiosas, fueron también solicitados); sin embargo, la nueva configuración de la sociedad después de la Independencia manifestó, sobre todo entre las altas esferas, sus requerimientos de legitimación a través del retrato.

En el México de mediados del siglo pasado dos célebres pintores destacaron, principalmente, en el retrato: Pelegrin Clavé y Juan Cordero. En su época ambos gozaron de gran fama y prestigio, debido a la calidad de su obra. A través de estas dos figuras, los principios neoclásicos que imperaban en la Academia de San Lucas de Roma (donde adquirieron su formación tanto Clavé como Cordero) se difundieron en la enseñanza de la pintura en nuestro país, vía la Academia de San Carlos.

La norma aplicada en San Carlos privilegió la relación entre verdad y belleza. La primera cualidad tiene que ver con la naturaleza, y la segunda con los principios de "noble sencillez" y "serena grandeza" en la actitud y en la expresión ${ }^{6}$ definidos por Winckelmann, el teórico que encabezó el

${ }^{6}$ Cfr. Johann J. Winckelmann, Reflexiones sobre la imitación del arte griego en la pintura y la escultura, Barcelona, Ed. Ludwig, Nexos, 1987. 
movimiento neoclásico surgido a mediados del siglo XVIII. Cabe señalar que, en el curso de ese estilo, la obra de Rafael constituyó el modelo a seguir en la pintura.

Desde el punto de vista de la crítica de arte, se elogiaron en nuestro país los siguientes atributos en la pintura de retrato: el carácter; la propiedad; el exacto parecido; la naturalidad; la claridad; la buena proporción de las formas; la justa representación de las mismas; la precisión; el buen gusto como sinónimo de lo agradable; la armonía en la composición, el dibujo, el color, el tema, la luz y los objetos del espacio; la sencillez; la delicadeza matizada por la suavidad y la dulzura; la gracia y el sentimiento delicado que se contrapone a la exageración teatral. ${ }^{7}$

\section{De la Academia al Estudio Fotográfico}

Algunas noticias dan cuenta del temprano vínculo que establecieron, antes de conformar la compañía Cruces y Campa, sus fundadores. Corría el año de 1853, cuando la lista de los estudiantes destacados en la clase de anatomía de la estampa reunió, en la Academia de San Carlos (probablemente por vez primera), a Antioco Cruces y Luis Campa, entre otros esmerados alumnos ${ }^{8}$ Más tarde el segundo pasaría a sumarse a la relación de profesores, al frente de la cátedra de grabado en hueco y grabado en lámina. Esto ocurrió en 1860 y sabemos, con toda seguridad, que se mantuvo en el puesto hasta $1881 .{ }^{9}$ Dentro de ese periodo transcurriría, precisamente, la vida de la famosa compañía fotográfica.

\section{Los retratos de Cruces y Campa}

Establecida en la ciudad de México en 1862, la compañía fotográfica Cruces y Campa retrató a la distinguida élite metropolitana, durante quince años, aproximadamente. Al igual que la mayoría de los de su gremio en aquella época, se dedicó a trabajar de manera profesional. ${ }^{10}$ Podemos

${ }^{7}$ Cfr. Justino Fernández, El arte del siglo XIX en México, México, Universidad Nacional Autónoma de México, 1967.

${ }^{8}$ Cfr. Eduardo Báez Macías, Guía de la antigua Academia de San Carlos. 1844-1867 (tercera parte), México, Universidad Nacional Autónoma de México, Instituto de Investigaciones Éstéticas (Estudios y Fuentes del Arte en México, XXXV), 1976 Documento 4401.

${ }^{9}$ Cuentas del Tesoro Federal. Periodo fiscal de junio de 1881 a junio de 1882.

${ }^{10}$ Esta situación es compartida por el común de los fotógrafos retratistas de su época. El fotógrafo aficionado, como el que certifica la firma "Lara" - según lo consigna la inscripción 
adivinar que tal circunstancia involucró, en cierto modo, una subordinación de su trabajo al gusto del cliente y, al mismo tiempo, al patrón habitual del trabajo profesional, para competir en el mercado. En este contexto tampoco podemos olvidar el propósito para el cual se retrataba la gente En los retratos tarjeta de visita se reconoce una función muy particular: el regalo, el intercambio o el medio publicitario. Lo que finalmente se puede adivinar, a riesgo de aventurar un hecho que no ha sido comprobado suficientemente, es que su destino final era el álbum.

Considerando lo anterior, parte de la obra de Cruces y Campa muestra el patrón generalizado en el retrato tarjetas de visita. Muchos retratos de los notables del gobierno mexicano, tomados de cuerpo entero o de tres cuartos de figura, dan cuenta de ello (figuras 1, 2 y 3).

Otros, en cambio, revelan una atención individual en la persona que posa frente a la cámara. Son retratos en los cuales sobresale la agudeza para capturar oportunamente un gesto singular; una fugaz sonrisa; la inconfundible mirada de la persona que posa frente a la cámara; o la concertación de la pose con la personalidad del retratado (figuras 4, 5 y 6). En estos casos se puede advertir el dominio absoluto, por parte de Cruces y Campa, de su trabajo y, ante todo, una esmerada atención y sensibilidad para dar con la individualidad del modelo.

En este segundo grupo de retratos se incluyen aquellos que nos interesa comentar. Como ya se había señalado en los primeros párrafos, lo común en ellos es la afinidad que tienen, a primera vista, con algunos retratos pintados por los máximos exponentes del género retratístico en aquella época: Pelegrin Clavé y Juan Cordero. Ello nos anima a suponer que el interés depositado en la solución de algunos de sus trabajos, planteó a Cruces y Campa la posibilidad de echar mano del bagaje que ofrecía el retrato pintado de acuerdo con las normas académicas. En adelante nos detendremos a examinar tal supuesto.

\section{La fotografia y la pintura, dos caminos que se cruzan}

A) El escenario y los planos

Por lo general el manejo del escenario y de los planos en que se representa el retrato fotográfico de cuerpo entero, en formato tarjeta de visita, tiende

que acompaña su nombre al reverso de una fotografia-fue hallado como caso único en los archivos revisados hasta ahora. 
DOI: http://dx.doi.org/10.22201/iie.18703062e.1992.63.1649

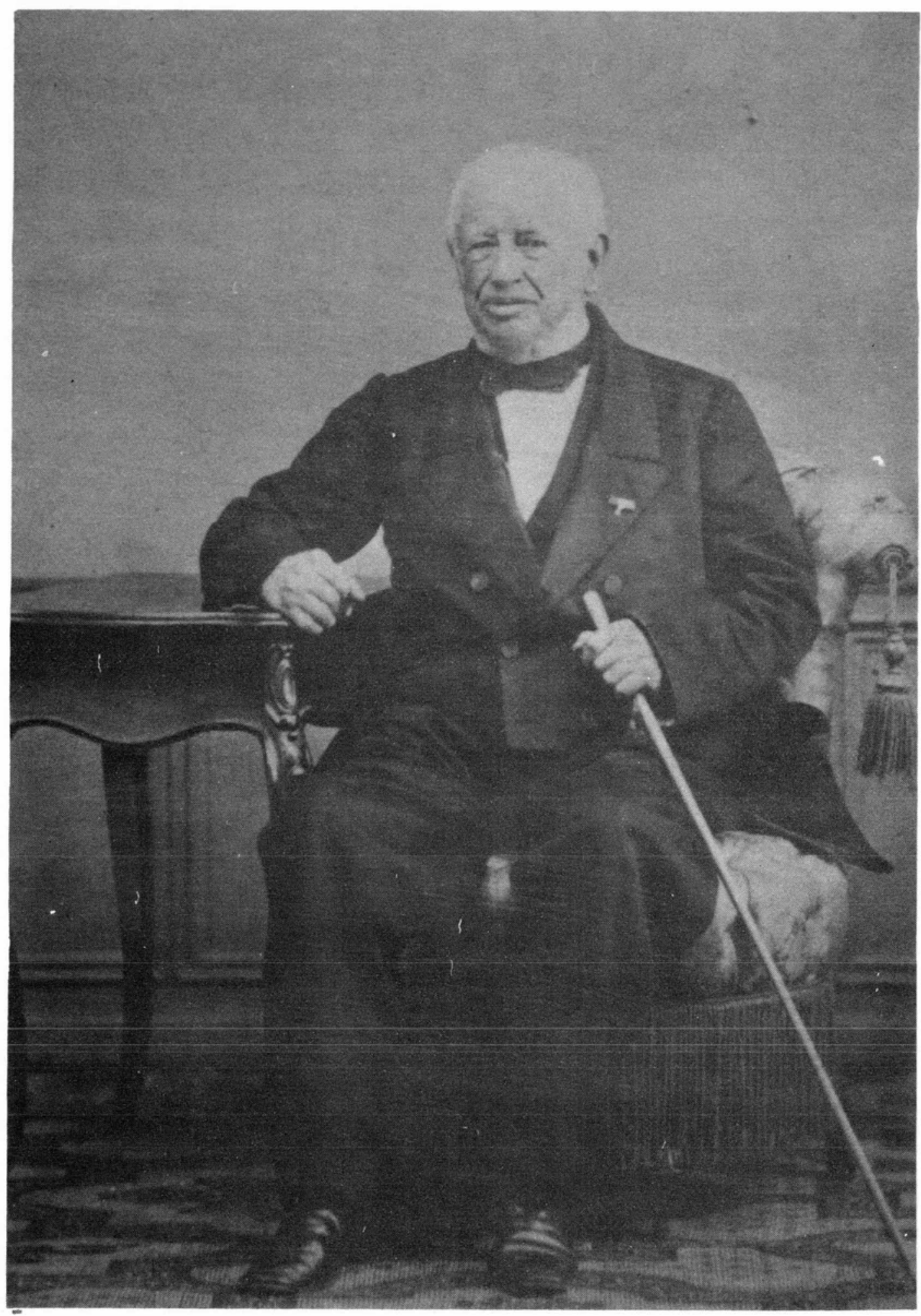

1. Gral. Bernardo Miramón. 
DOI: http://dx.doi.org/10.22201/iie.18703062e.1992.63.1649

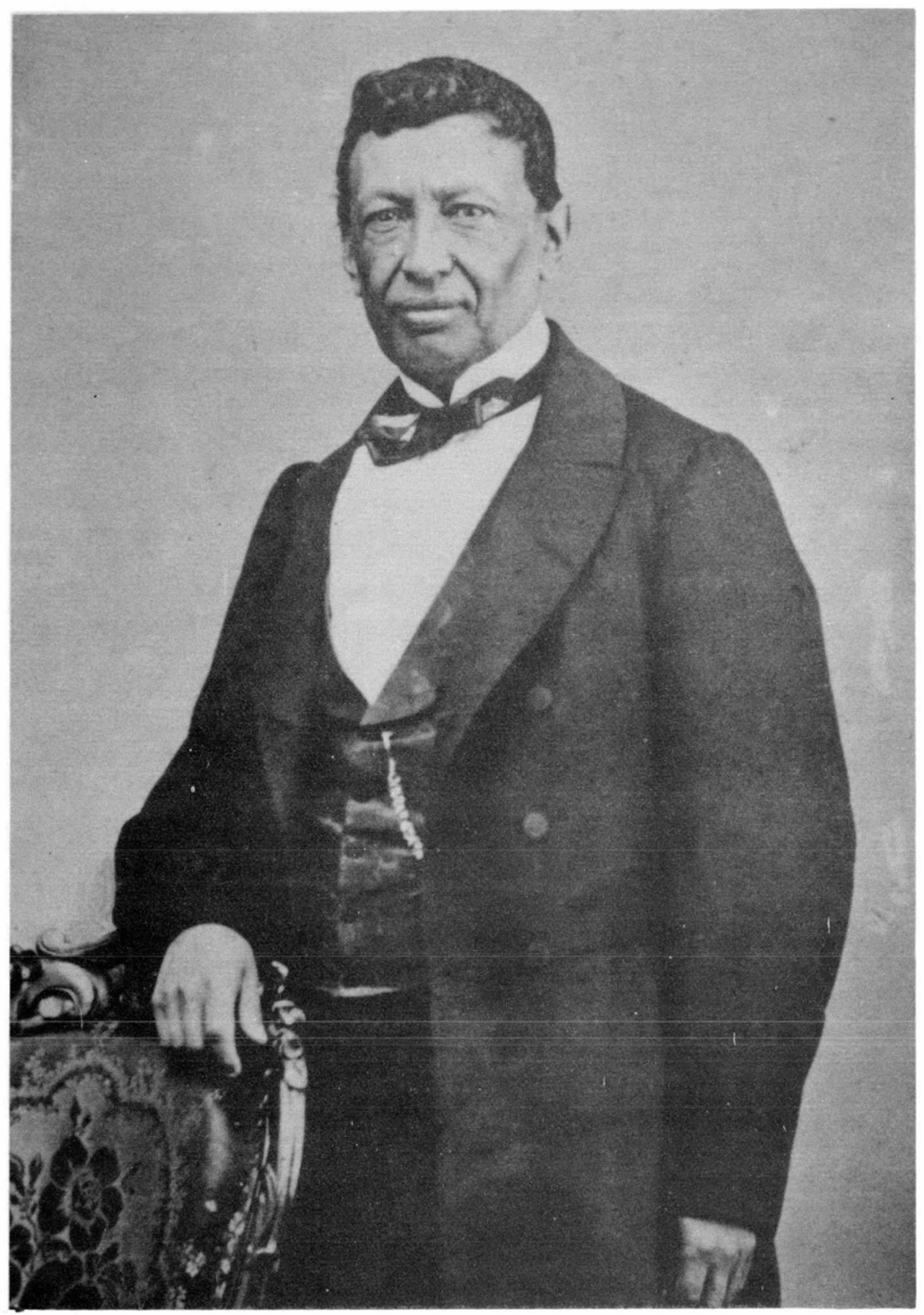

2. Gral. Torres. 


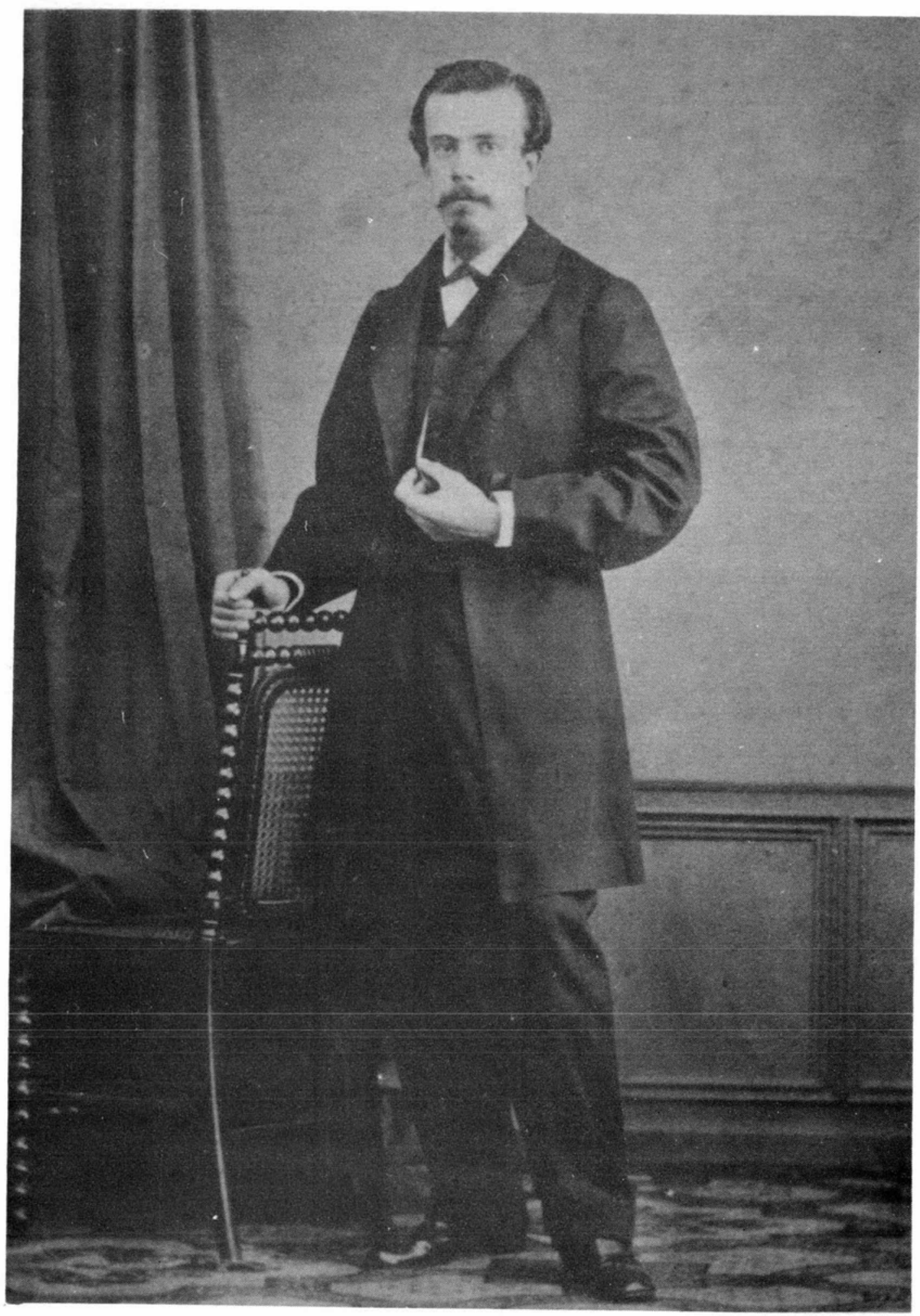

3. Francisco González de Cosío.

La sociedad Cruces y Campa no estuvo ajena al manejo de las convenciones formales generalizadas en el retrato tarjeta de visita. 


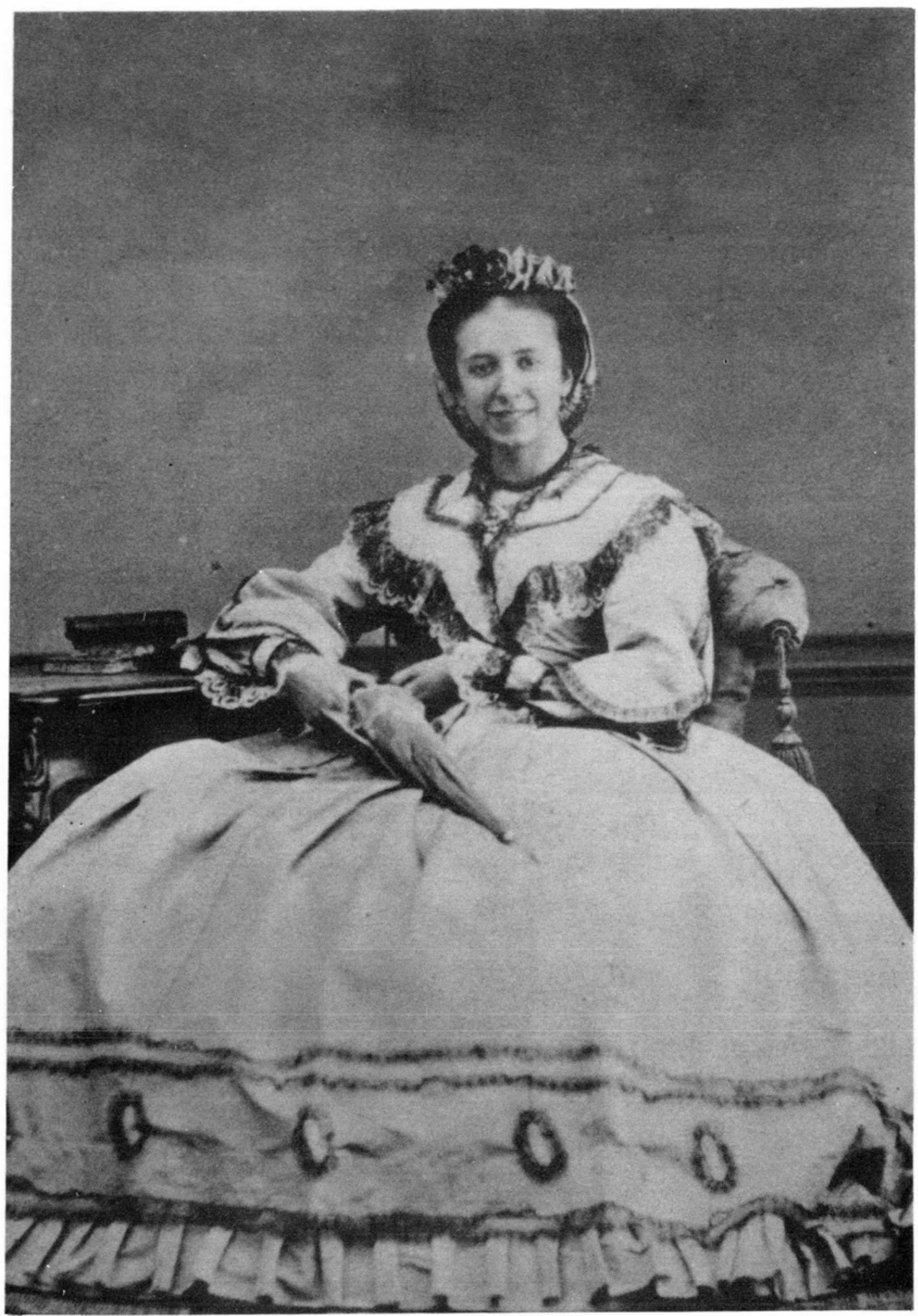

4. Retrato de dama no identificada. 


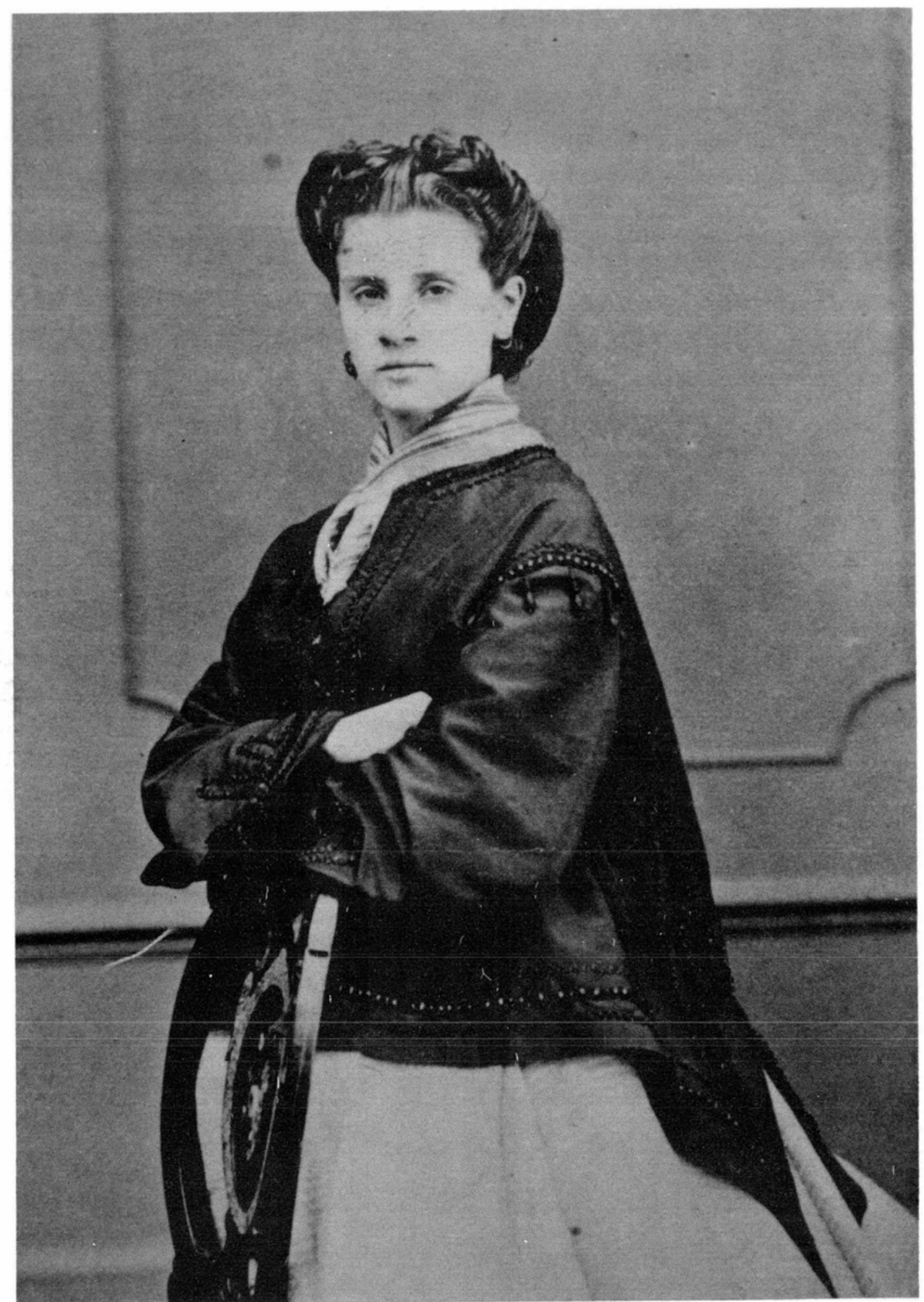

5. Retrato de dama no identificada. 
DOI: http://dx.doi.org/10.22201/iie.18703062e.1992.63.1649

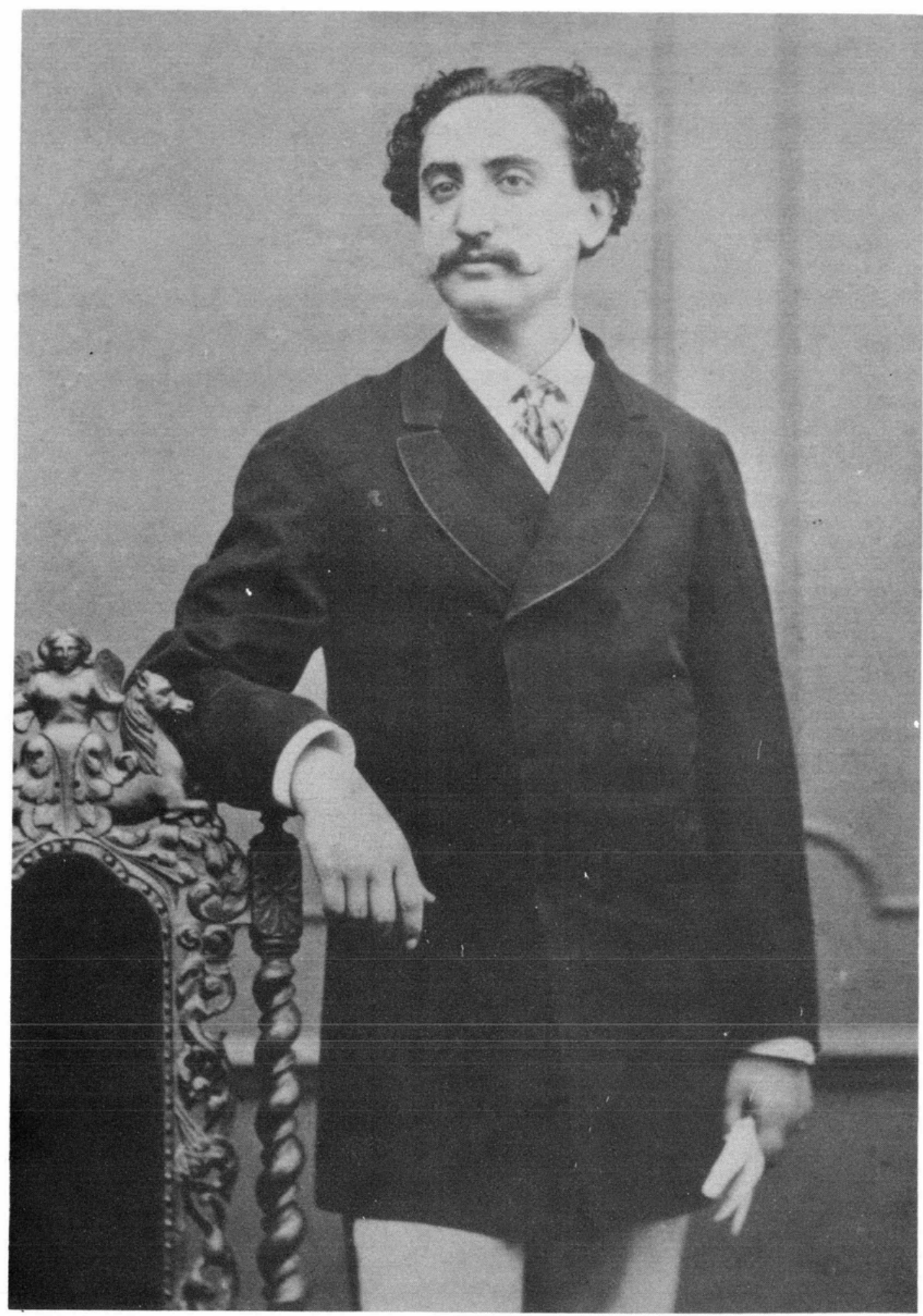

6. Juan A. Mateos.

Cruces y Campa supieron captar un gesto singular; una fugaz sonrisa; o concertar de la pose con la personalidad del retratado. 
DOI: http://dx.doi.org/10.22201/iie.18703062e.1992.63.1649

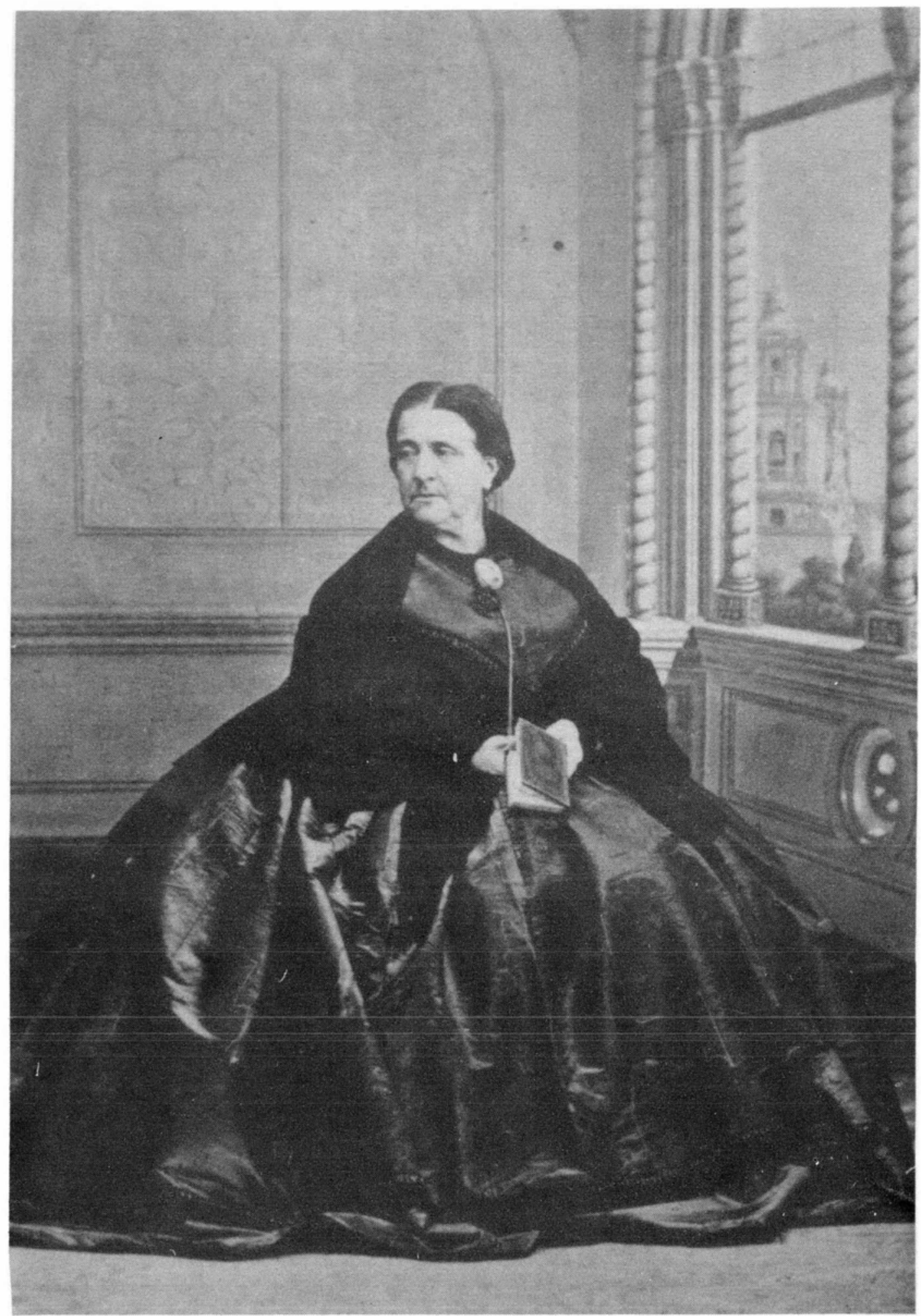

7. Cruces y Campa. Retrato de Rosa Obregón de Uraga.

A pesar de no ser muy agraciada, la mujer aparece ennoblecida por obra de los fotógrafos. 


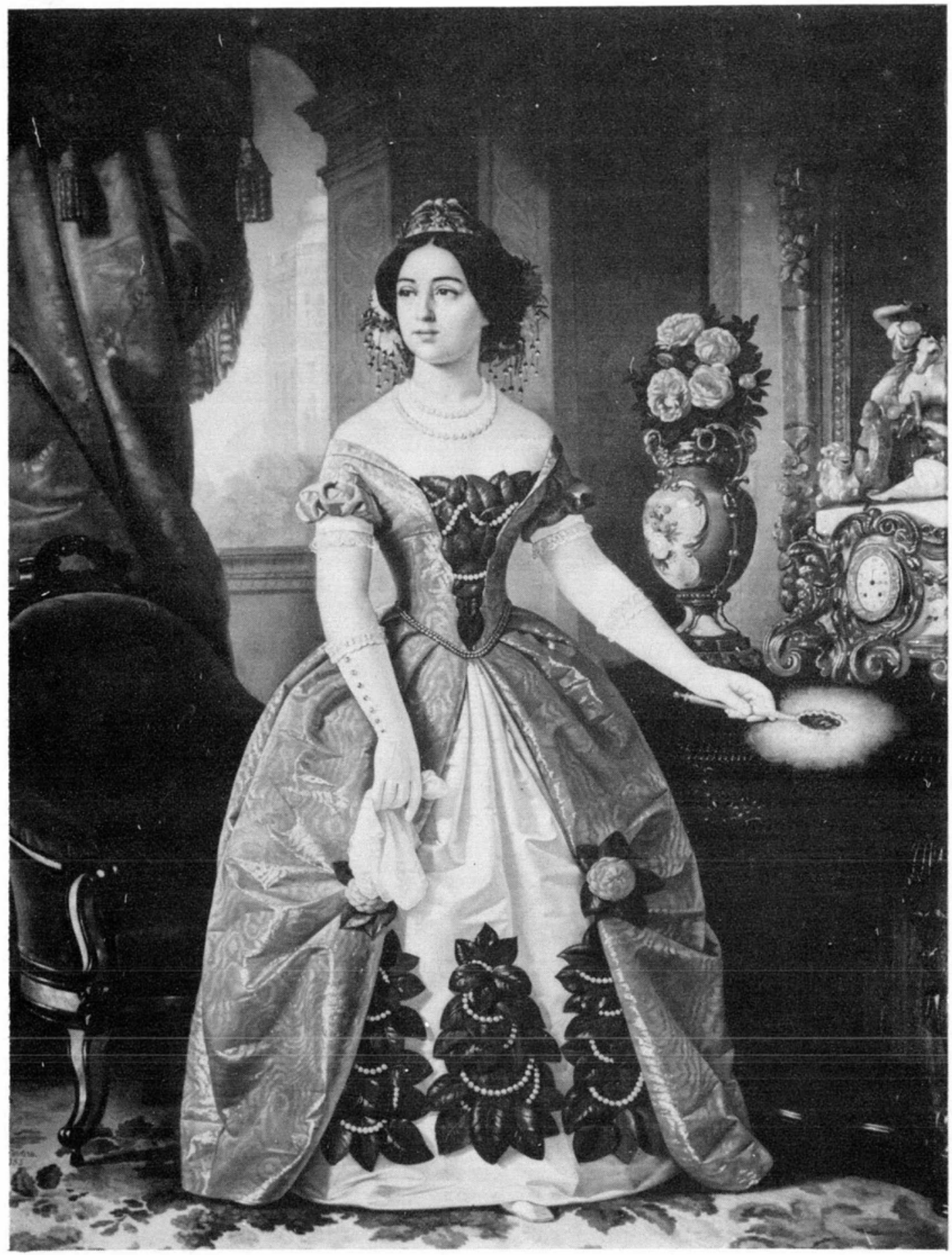

8. Juan Cordero. Retrato de Dolores Tosta de Santa Anna.

El pintor agota las posibilidades que ofrece de pie doña Dolores Tosta para ponderar valores pictóricos. 


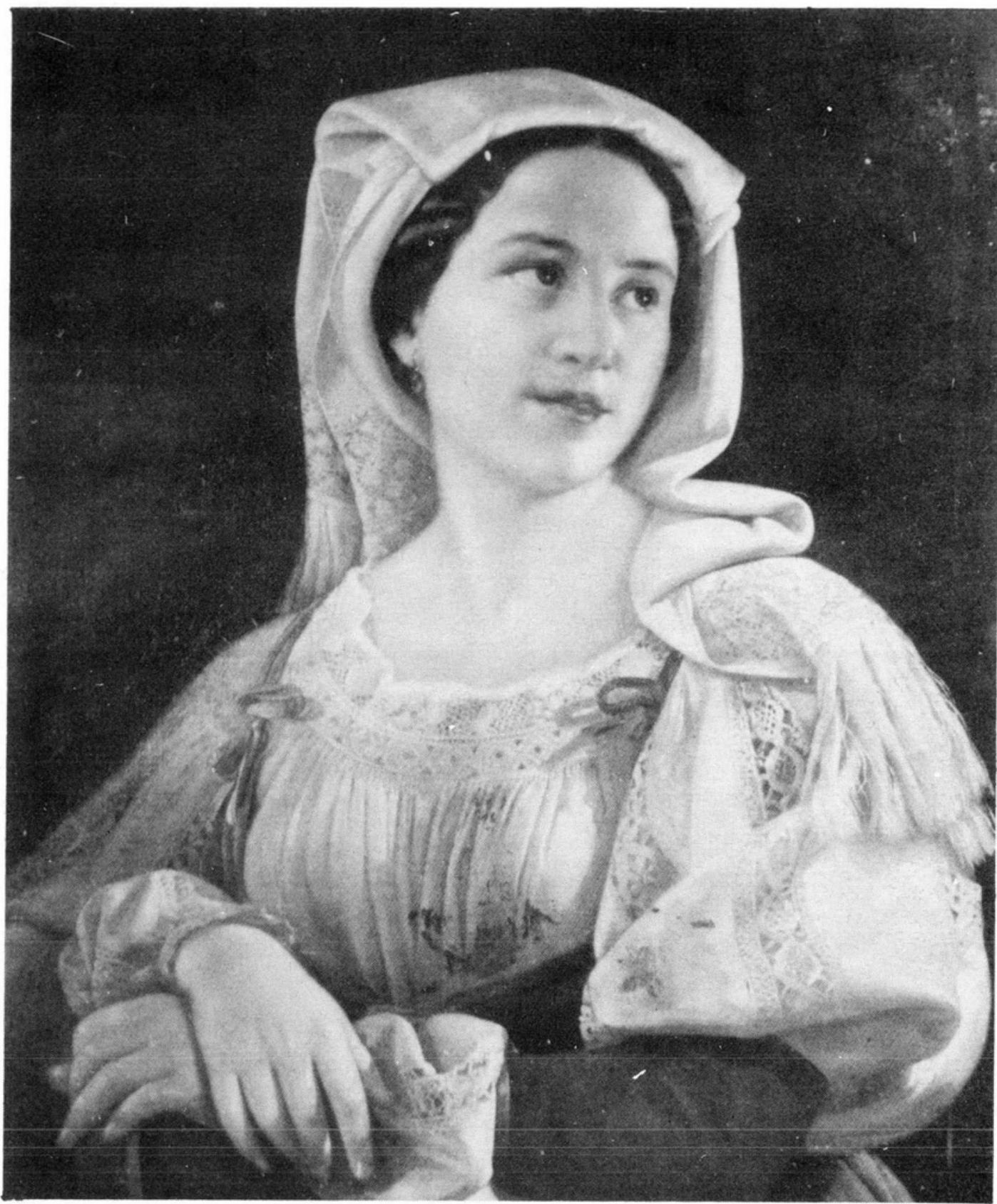

9. Juan Cordero. Napolitana.

La composición sugiere una singular imagen de belleza femenina, donde lo sublime tiene una importancia fundamental. 


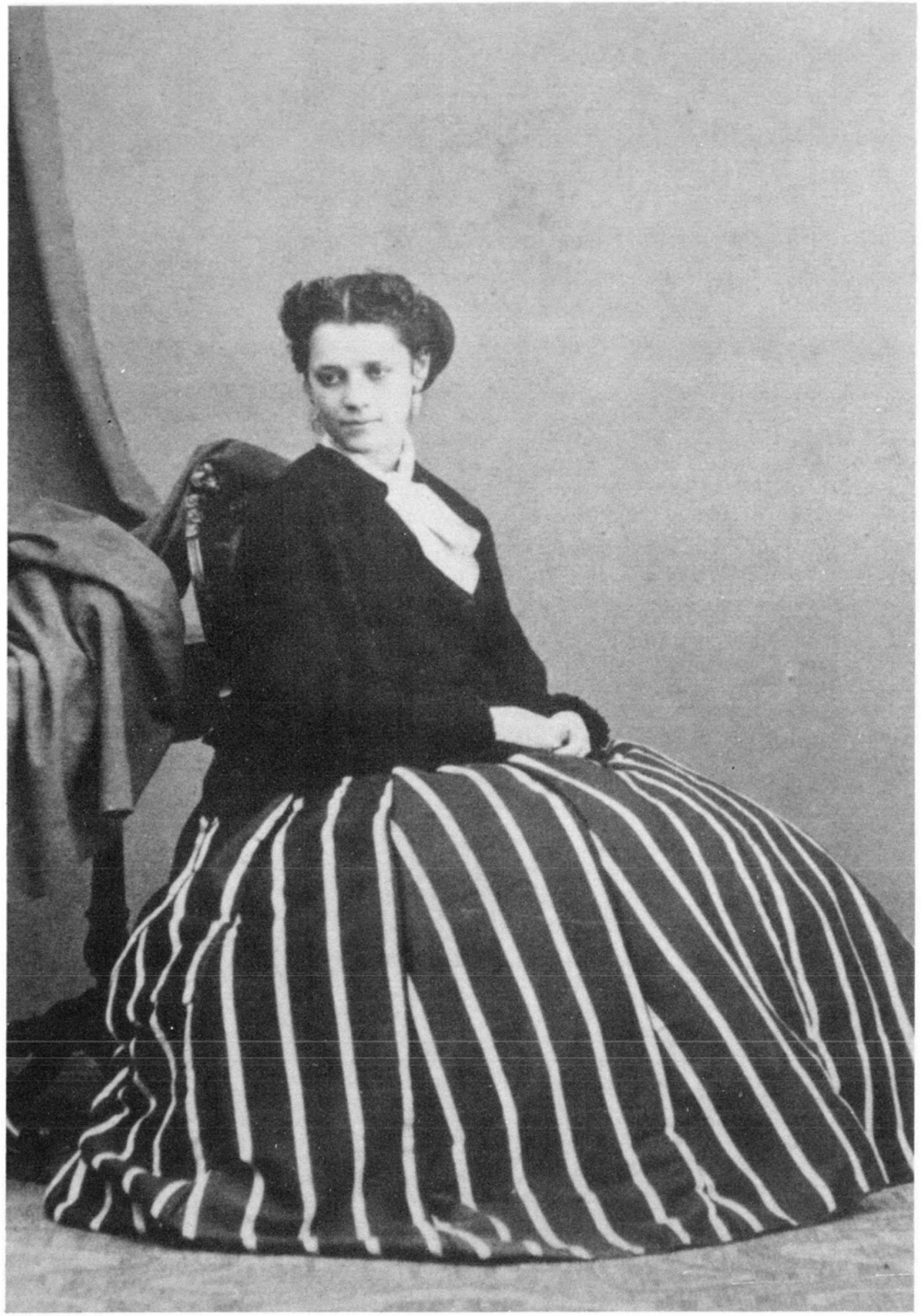

10. Cruces y Campa. Retrato de Concepción Méndez.

Lo fotográfico se impone con el gesto: una mirada y una leve sonrisa instantáneas, tangibles. 
DOI: http://dx.doi.org/10.22201/iie.18703062e.1992.63.1649

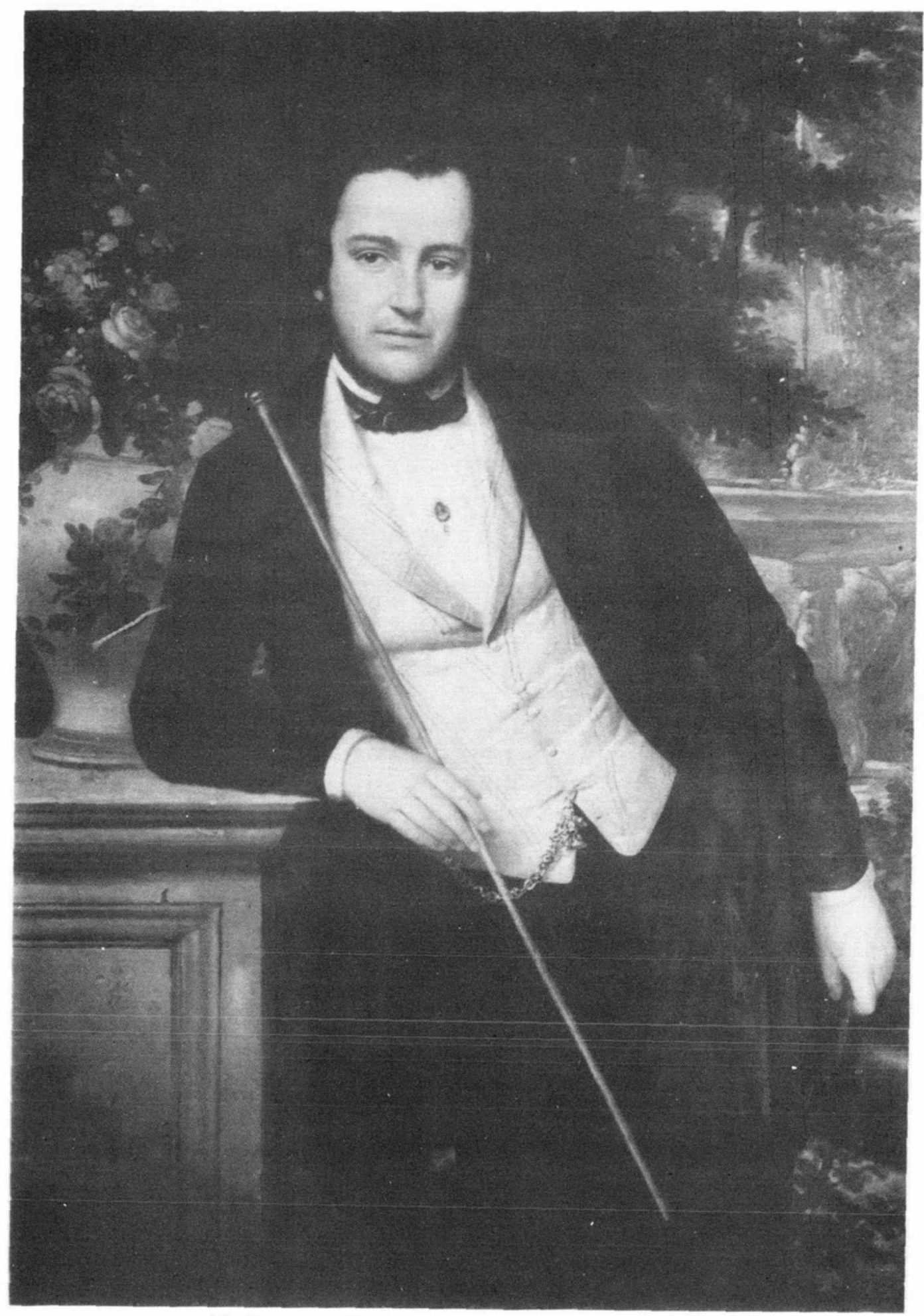

11. Pelegrín Clavé. Retrato de Rafael Cancino. 


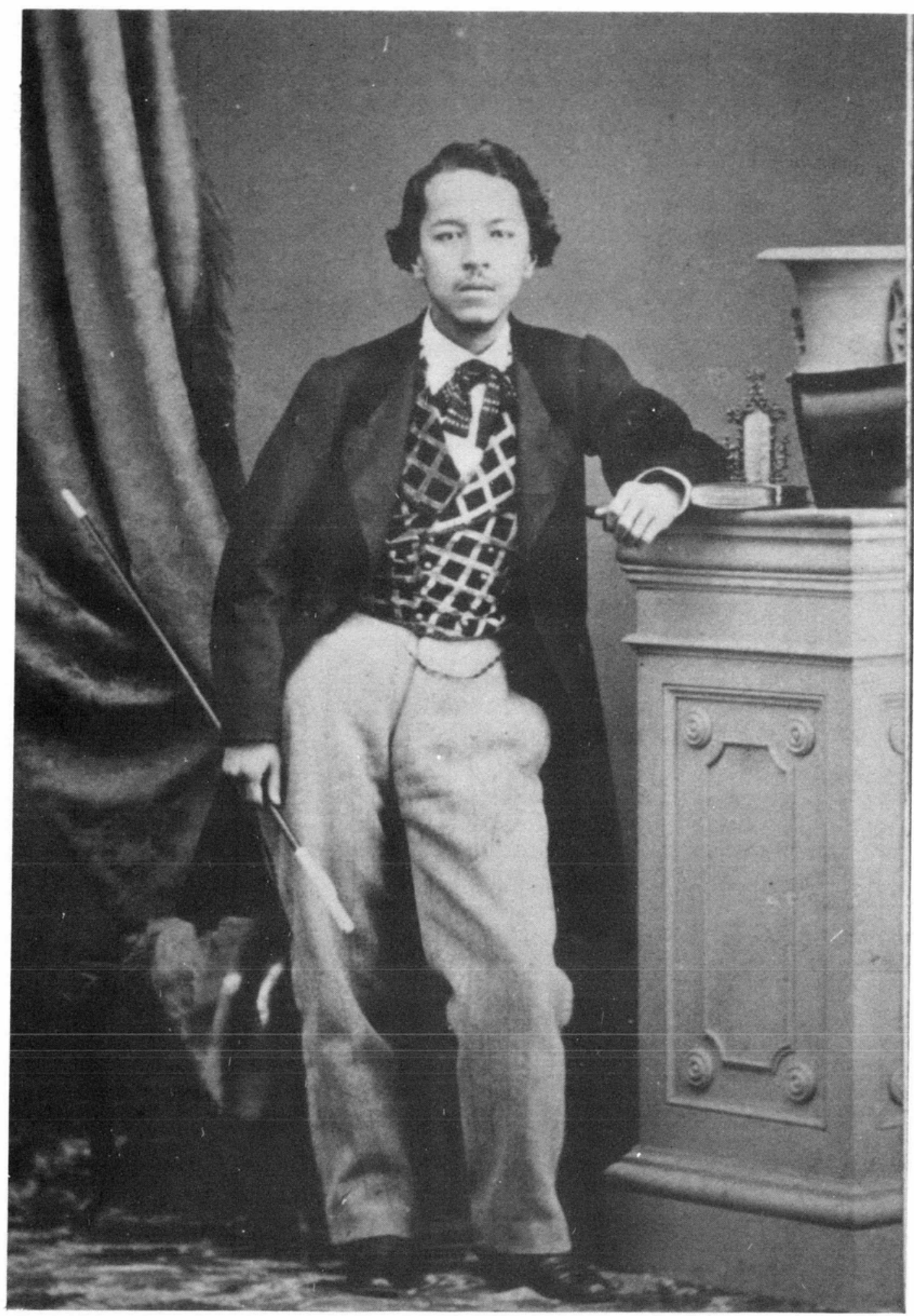

12. Cruces y Campa. Retrato de caballero.

Mantener inmóvil al modelo durante un tiempo determinado fue el problema común que tuvieron que resolver tanto el fotógrafo como el pintor. 
a ser teatral: el personaje en el primer plano tiene un fondò detrás que es, en muchos casos, un telón pintado. Mediando entre ellos se disponen algunos elementos ornamentales que completan la ambientación: casi nunca falta una mesa o una silla, una balaustrada o una columna. En el caso concreto del retrato de Rosa Obregón de Uraga la monotonía de ese esquema se modifica (figura 7). A través de la conjunción de los planos que sugiere el escenario y la pose del personaje, Cruces y Campa resuelven una construcción espacial que realza la figura retratada: una de las damas de palacio durante el imperio de Maximiliano. A pesar de no ser muy agraciada, la mujer aparece ennoblecida por los fotógrafos. Pues bien, entre esta fotografía y el retrato de Dolores Tosta de Santa Anna, pintado por Juan Cordero, existe una innegable cercanía (figura 8).

Ante todo llama la atención la ventana abierta a través de la cual se miran las torres de la Catedral Metropolitana en ambos retratos. Este recurso escenográfico constituye un rasgo de verosimilitud buscado tanto por los fotógrafos como por el pintor. Cuando Cruces y Campa hicieron el retrato de la señora Obregón, su estudio se localizaba precisamente a un lado de la Catedral. Cordero, por su parte, nos sugiere que la representación de la señora de Santa Anna tiene lugar en el lado opuesto al de los fotógrafos: el Palacio Nacional. La alusión a un espacio real está presente gracias a la supuesta vista del exterior desde el lugar donde posan las retratadas. Además de contar con la ventana abierta, en los dos retratos el espacio es profundizado con la insinuación del ángulo donde convergen las dos paredes de la pieza; de esta manera ambas provocan la sensación de penetrar en el interior de la habitación, con lo que se logra un efecto de singular intimidad.

Lo que hasta el momento ha sido señalado es sólo una parte de nuestras observaciones, que tienen que ver con las semejanzas; para nuestros propósitos lo menos importante. Lo realmente significativo y esencial lo hallamos en las diferencias. La manera como se resuelve la imagen en la fotografía aparta totalmente a esta última de la pintura. La naturaleza de los instrumentos utilizados en cada caso se encarga de disuadir su aparente cercanía.

Si bien ambas personas aparecen de cuerpo entero, están situadas en el eje central de la composición y el giro del cuerpo es similar (el rostro voltea en dirección opuesta a la posición del cuerpo), la pose tiende a destacar distintos aspectos en la imagen. El pintor agota las posibilidades que ofrece de pie doña Dolores Tosta; la esbeltez, el vestido que porta y la dignidad que resulta de la combinación de estos dos aspectos, son aprovechados para subrayar el rango social de tan distinguida dama $y$, ante 
todo, para ponderar valores pictóricos tales como la línea, el color y la textura que logra el pincel. Por lo que atañe a la señora Obregón, observamos que los fotógrafos resaltan especialmente la templanza inherente a la edad de dicha señora; para ello, la serenidad y el aplomo que refleja se refuerzan con la disposición que guarda la modelo, pues su figura se impone en la composición con una forma piramidal sólidamente definida. Además, las posibilidades de la cámara son aprovechadas a plenitud, al imponerse la captura del instante, del gesto espontáneo en el cual casi podemos advertir el inmediato parpadeo en los ojos de la dama e, incluso, su tenue voz.

A pesar de lo difícil y aventurado que puede significar la interpretación de las tonalidades que observamos en cualquier impresión en albúmina (debido a que, según lo advierte Reilly, el deterioro está presente en la mayoría de las fotografías hechas con este proceso), ${ }^{11}$ no pasaremos por alto este aspecto que indica, aunque sea de una manera aproximada, la calidad del trabajo de Cruces y Campa. Los medios tonos dominan el escenario y refuerzan la expresión de la fotografiada, creando una atmósfera apacible, donde resalta, con vestido y mantilla oscuros, la sobria figura.

Además de lo que se ha puntualizado, es importante tener en cuenta las diferencias en el tamaño de los retratos que se están comparando: la pintura es de grandes dimensiones, en tanto que la fotografía apenas mide nueve por seis centímetros. Por sus tamaños, la primera estaba destinada a ser colocada en un espacio que permitiera lucir ampliamente sus cualidades pictóricas; la fotografía, a final de cuentas, probablemente no pasaría de estar en un álbum, donde permanecería al lado de otros retratos.

Si se considera que la pintura se realizó en 1855 y que la fotografía de la dama de palacio fue posterior (seguramente entre los años de 1864 y 1867), se puede decir que, para hacer el retrato de la señora Obregón, Cruces y Campa se apoyaron en el que Juan Cordero pintara de la Señora de Santa Anna. Algunas razones llevan a anticipar esta interpretación.

No se tiene plena certeza de que Cruces y Campa hayan conocido el cuadro de Dolores Tosta. Cuando Cordero expuso algunas de sus obras en la Academia de San Carlos -en diciembre de 1864- ese retrato no fue incluido en la muestra; ${ }^{12}$ tampoco se tiene conocimiento de una posterior exhibición pública de la citada pintura. Sin embargo, se puede adivinar que, de alguna otra manera, Cruces y Campa tuvieron noticias detalladas

11 "Entre el 90 y el $50 \%$ de las impresiones en albúmina se han desvanecido y han cambiado de color" en James Reilly, Care and Identification of 19 th Century Photographic Prints, Rochester, New York, Kodak, 1986, p 38

${ }^{12}$ Cfr. Báez, op. cit., documento 6625 . 
de ella. Seguramente su permanencia en la Academia los aproximó a la citada pintura.

\section{B) La pose en el retrato}

Otra situación, semejante a la anterior, se observa en la forma como resuelve Juan Cordero la postura en los retratos de La mora o de la Napolitana (figura 9), retomada por Cruces y Campa en el retrato de Concha Méndez (figura 10). También en este caso las pinturas se realizaron con anterioridad al momento en que se puede estimar que fue hecha la fotografía. Aquéllas datan de la época en que Juan Cordero estuvo pensionado en Roma, es decir, entre 1846 y 1853. La fotografía se puede remitir a los años del Segundo Imperio. En este caso también hallamos una aparente influencia de la obra pictórica citada sobre la fotografía. El hecho de que las primeras obras de Juan Cordero se dieran a conocer al público en 1850 (en la segunda exposición de la Academia) y que, desde entonces, la alta calidad del pintor fuera reconocida por los alumnos de San Carlos ${ }^{13}$ (entre quienes se contarían, unos años después, Antioco Cruces y Luis Campa) nos lleva a deducir lo anterior.

El tratamiento del rostro girado en dirección opuesta al torso y las manos acentúa, en el caso de la pintura, la armonía entre la gracia del gesto y la sublime belleza de la joven. Además del tipo de modelo utilizado por Juan Cordero en esos retratos, la pose acentúa la sensualidad. Tal solución adoptada por el pintor mexicano, cuenta con el antecedente iconográfico de la madona, en el cuadro de La Virgen con el niño, cuyo autor es El Perugino, maestro de Rafael. Esta influencia no es casual, llega desde El Perugino a Juan Cordero a través de los prerrafaelistas y la Academia de San Lucas.

En los retratos del pintor mexicano la composición sugiere una singular imagen de belleza femenina, donde lo sublime tiene una importancia fundamental. Se trata en ambos casos de un gesto ideal que contribuye a reforzar el modelo concebido por su autor; modelo que, por lo tanto, refleja una condición más etérea que terrenal.

El retrato de Concha Méndez se aparta de los que se han citado de Cordero, precisamente porque en ningún momento abandona su contacto con la realidad. Lo fotográfico se impone con el gesto; se trata de una mirada y una leve sonrisa instantáneas, tangibles -si es que se puede decir

${ }^{13}$ Cfr. Elisa García Barragán, El pintor Juan Cordero, México, Universidad Nacional Autónoma de México, Instituto de Investigaciones Estéticas, Fundación Juan Cordero, 1984. 
así-, captadas en el momento preciso por el agudo ojo de Cruces y Campa. Por otro parte, la toma de cuerpo entero hace que disminuya el impacto que pudiera provocar la expresión un tanto melancólica que se esboza en el semblante de la joven, distrayendo, de este modo, el efecto emocional; la falda ejerce un contrapeso y le da un carácter distinto a la composición, en comparación con las dos pinturas referidas. En la medida en que sólo miramos en estas últimas la mitad del cuerpo, la atención se detiene precisamente en el rostro, mientras que, en el otro caso, lo emotivo es atenuado al aparecer la figura completa del personaje. Es claro que, después de todo, el recurso común del giro del cuerpo tenga un efecto diferente en los trabajos aludidos. Distintas son las técnicas, distintos los valores ponderados en la creación de la imagen.

\section{C) El tiempo de pose como factor condicionante}

En la pintura de retrato y también en los retratos tarjeta de visita, se repite con mucha frecuencia aquella fórmula según la cual el modelo se sitúa junto a una columna o pilar truncos que le sirven de apoyo. Este recurso, ya convencional entre la utilería que forma parte del repertorio tanto de la pintura como de la fotografía, constituye un soporte auxiliar durante la ejecución del retrato y se integra de manera secundaria en la composición, cuyo centro de atención sigue siendo el personaje retratado. No obstante, algunos trabajos muestran detalles que ofrecen variaciones en el acomodo del modelo, sobre todo en lo que se refiere a la disposición de brazos y manos, como puede observarse en el retrato de Rafael Cancino, pintado por Clavé en 1850 (figura 11). De esta obra, Cruces y Campa retoman, en la fotografía de un personaje no identificado, la manera de resolver la postura del modelo (figura 12).

Salvo las variaciones en el emplazamiento de la columna -que en la pintura aparece del lado izquierdo del espectador y en la fotografía en el derecho-y en el encuadre -que se corta en la obra de Clavé a la altura de las rodillas, mientras que en la de Cruces y Campa abarca la figura completa-, el resto guarda similar composición. En ambos retratos el cuerpo, ligeramente arqueado, delinea una suave curva a la cual se amolda el brazo que cae lateralmente, mientras que el otro brazo permanece recargado sobre el pedestal. A esta disposición principal se opone otra línea curva más corta, que parte del rostro y se prolonga a través de las manos. El ritmo que sugiere la composición, se aleja de la fórmula habitual en la cual la pose tiende a ser más rígida. 
En el retrato de Clavé la cadencia resuelve una composición suelta y afable, y lo mismo se observa en la fotografía. Sin embargo, hay detalles que delatan diferencias en los retratos que estamos comparando. Clavé armoniza en su pintura la curva que sugieren manos y rostro, con una ligera inclinación de la cara; es decir, acude a la corrección en el dibujo para mantener el ritmo y para dar a la composición la solución deseada. Por el contrario, en la fotografía no hay cabida para la afectación; se impone la sinceridad del sujeto natural, de carne y hueso; de acuerdo con ello, la cara permanece erguida.

La actitud del modelo, en el retrato de Clavé, está subordinada a la armonía interna de la imagen, enfatizada por el encuadre. Además, el dominio que tiene el pintor sobre la elección de los colores es aprovechado para resolver el cuadro, de acuerdo con su concepción ideal. Esto último que hemos anotado queda fuera del control del fotógrafo.

Retomando la circunstancia que relaciona particularmente los retratos comparados, es decir, la presencia de utileria (misma que pone de manifiesto la necesidad de que fotógrafo y pintor requieran la inmovilidad del modelo), volvemos sobre el punto que nos interesa subrayar.

A pesar de que la cámara sólo necesitaba un breve instante para que fuera tomado el retrato, no dejaron de haber limitantes técnicas en la fotografía que hicieron necesaria la pose. Sólo de manera vaga se puede estimar el tiempo que el sujeto posaba frente a la cámara en aquellos años; las eventualidades del estado atmosférico o los recursos de que estuviera provisto el estudio del fotógrafo, hacían muy variable el tiempo necesario para la toma del retrato. Lo primero porque la única fuente lumínica era el sol (sólo años más tarde se contaría con la luz de magnesio). Lo segundo tenía que ver con diversos elementos; por ejemplo, el tipo de vidrio utilizado en los ventanales del estudio y el mantenimiento que solía dárseles a éstos, tenían efectos directos en la calidad de la luz que penetraba en el interior del estudio. Tomando en cuenta lo anterior, entre otros factores, se estima que el tiempo requerido para la toma del retrato fotográfico oscilaba, aproximadamente, entre dos y once segundos.

Así, el problema común que tenían que resolver tanto el fotógrafo como el pintor, esto es, mantener inmóvil al modelo por un determinado tiempo, los aproxima en la forma de solucionarlo. Para facilitarse el trabajo, ambos requirieron apoyos para el modelo; al respecto podemos reconocer que el pintor ya contaba con un repertorio que lo mismo serviría para el fotógrafo.

En suma, de todo lo que ha sido puntualizado hasta el momento, destacan dos aspectos fundamentales que circunscriben los retratos que hemos analizado de Cruces y Campa: 
Primero, el hecho de que tal sociedad fotográfica no se limitó a aplicar mecánicamente la fórmula sugerida por la moda que impusiera Disdéri, sino que se apoyó en otros medios alternativos.

Segundo, no obstante que la pintura de retrato de tipo académico, de mediados del siglo pasado, constituyó una fuente iconográfica para los retratos fotográficos examinados, en Cruces y Campa hemos observado la maduración de un trabajo que resuelve de una manera propia la factura del retrato. No admite dudas en cuanto a su originalidad, pues al intentar aproximarlo con la pintura ha mostrado que resplandece, por sí mismo, con una luz propia. 